\title{
Em Busca do Santo Grau - Jogo Educacional com Desafios Customizáveis
}

\author{
Rogério A. Bordini, Joice Lee Otsuka, Delano M. Beder, Luiz Valério Neto, \\ Douglas A. M. Barbino, Catarine Santana Onhuma, Ana Esther R. de Camargo, \\ Paulo Henrique Ferreira Fontoura Junior
}

Laboratório de Objetos de Aprendizagem - Universidade Federal de São Carlos

(UFSCar) - Caixa Postal 676 - CEP: 13565.905 - São Carlos/SP - Brasil

\footnotetext{
rogerio.bordini@sead.ufscar.br,\{joice, delano\}@dc.ufscar.br, douglas-448@hotmail.com, \{luizvneto, catarine.ohn, annaerodrigues, paulojunior. fontoura\}@gmail.com
}

Resumo. Quando um professor se propõe a inserir um determinado jogo educacional em sala de aula, ele se vê na difícil tarefa de selecionar aquele que esteja em consonância com suas demandas de ensino, uma vez que a grande maioria dos jogos já possui conteúdos pré-determinados e inalteráveis. Assim, o objetivo deste artigo é apresentar o jogo eletrônico educacional Em Busca do Santo Grau, game 2D de aventura para PC que permite a customização do conteúdo de puzzles e outros recursos no jogo. São apresentados os principais elementos de design, bem como suas possibilidades de customização e as demandas que motivaram a realização desse projeto.

\section{Cenário de uso}

Nos últimos anos escolas e universidades vem a cada vez mais ganhando adeptos em relação à utilização de jogos na educação. Inúmeras pesquisas têm demonstrado os benefícios que o alinhamento entre games e estratégias educacionais pode resultar em processos de ensino e aprendizagem. Contudo, muitos professores podem se sentir confusos no momento de trazer um jogo para suas aulas, pois nem sempre encontram aqueles que possuem os conteúdos e/ou mecânicas mais consonantes às suas demandas pedagógicas. Além do mais, existem outros motivos que dificultam a implementação de jogos educacionais nas escolas, como a ausência de computadores capazes de suportar gráficos de jogos mais complexos, falta de tempo por parte dos professores em analisar todas as funcionalidades de um dado jogo para extrair deste os elementos que poderão ser trabalhados pedagogicamente e, por fim, a dificuldade de alinhamento dos objetivos de jogos comerciais para os padrões estaduais e locais (Nogueira, Chaimowicz e Prates, 2013).

Assim, o jogo Em Busca do Santo Grau surge como uma alternativa para auxiliar professores do ensino básico e superior que queiram trazer em um recurso digital os conteúdos que desejam trabalhar com os alunos de forma lúdica. Devido às várias possibilidades de customização de conteúdo que o jogo oferece - como inserção de

\footnotetext{
${ }^{1}$ Ver Gee (2007, 2005), Salen et. al. (2010), Squire (2007) e McGonigal (2011).
} 
VII Congresso Brasileiro de Informática na Educação (CBIE 2018)

Anais dos Workshops do VII Congresso Brasileiro de Informática na Educação (WCBIE 2018)

links e perguntas integradas em situações-problema que o jogador precisa solucionar ao longo de uma narrativa pré-estruturada - o professor terá em mãos um recurso lúdico, simples e gratuito que poderá atender suas demandas educacionais.

Este trabalho está sendo desenvolvido no escopo do projeto Recursos Educacionais Multiplataforma Abertos na Rede (REMAR) ${ }^{2}$, que visa prover uma plataforma de jogos educacionais abertos na qual é possível a criação de instâncias customizadas de jogos diretamente pelo professor, a partir de modelos de jogos abertos customizáveis.

\section{Desenvolvimento}

O jogo Em Busca do Santo Grau surgiu a partir dos seguintes requisitos levantados e propostos à equipe desenvolvedora:

- Desenvolvimento de narrativa e estética que cativassem diversos públicos;

- Narrativa e estética neutras e que possam ser reutilizadas para diferentes conteúdos e contextos, favorecendo o reuso;

- Mecânicas diversificadas, com o intuito de ampliar o reuso por diferentes professores, com diferentes objetivos educacionais e também para cativar estudantes com diferentes perfis;

- Projeto que possa integrar módulos com diferentes mecânicas e conteúdos, dando flexibilidade ao professor de combinação e customização de diferentes módulos, de acordo com os seus objetivos educacionais.

- Favorecer a colaboração com outros grupos de desenvolvimento de jogos, por meio da criação de novos módulos para o jogo.

- Oferecer pontos de customização de modo que professores de diferentes áreas de conhecimento consigam adaptar facilmente o conteúdo de desafios específicos de acordo com suas necessidades pedagógicas;

Após uma análise cuidadosa dos requisitos, foi dado início à concepção do jogo, cujo processo envolveu momentos de brainstorming, criação de storyboards, pesquisas relacionadas a jogos customizáveis e/ou educacionais e prototipação. $\mathrm{O}$ desenvolvimento do projeto tem sido realizado no Laboratório de Objetos de Aprendizagem (LOA) ${ }^{3}$ da UFSCar, espaço interdisciplinar de estudos e pesquisas de novas tecnologias e metodologias para o desenvolvimento de objetos de aprendizagem interativos abertos, concentrados na utilização dos games como objetos capazes de proporcionar um aprendizado lúdico ao estudante/jogador. A equipe responsável pelo projeto é composta por cinco estudantes de graduação (cursos de Ciência da Computação, Engenharia da Computação, Letras, Linguística e Imagem e Som) e um aluno o doutorado em Artes Visuais, que atuam como game designers, desenvolvedores, ilustradores e músicos, além de receberem apoio de docentes da área de Computação.

Quanto ao modo de organização das etapas de produção e de desenvolvimento dos elementos básicos do jogo, tem sido utilizado o organizador online Trello, por meio do qual é possível estipular datas para o cumprimento de prazos e organização de tarefas,

\footnotetext{
${ }^{2}$ Edital Programas de P\&D Temáticos da Rede Nacional de Ensino e Pesquisa (RNP) 2014-2015. Link: https://www.rnp.br/sites/default/files/chamadapublica gt-tematico 2014-v14.pdf

${ }^{3}$ Website do laboratório: http://www.loa.sead.ufscar.br
} 
VII Congresso Brasileiro de Informática na Educação (CBIE 2018)

Anais dos Workshops do VII Congresso Brasileiro de Informática na Educação (WCBIE 2018)

como criação de ilustrações, músicas, roteiros, storyboards, códigos, efeitos sonoros e planos de aprendizagem associados à narrativa e à customização. A comunicação da equipe tem ocorrido por meio do serviço de mensagens online Slack, o qual concentra sites de comunicação e compartilhamento de arquivos em um único ambiente. Por meio desta ferramenta, a equipe pôde integrar serviços como Trello, Google Drive e GitHub.

A customização e o acesso do jogo Em Busca do Santo Grau é possível por meio da plataforma REMAR ${ }^{4}$, ambiente que possibilita a customização de jogos educacionais por meio de modelos customizáveis.

A tecnologia empregada para implementação do jogo é a ferramenta de desenvolvimento Construct 2 (HTML5), motor de jogo que traz um sistema simples de "arraste-e-solte", oferecendo a possibilidade de construir toda a lógica do jogo usando uma série de scripts pré-prontos. Para criação de músicas e edição de áudios estão sendo utilizados, respectivamente, os programas Propellerhead Reason e o software gratuito Audacity.

\section{Apresentação do Software}

O jogo, de forma geral, narra a aventura de uma jovem estudante universitária, Ariel, que precisa passar por desafios sequenciais (puzzles) em uma universidade a fim de alcançar seu tão sonhado diploma de graduação (Fig. 1). A protagonista terá de aventurar-se por fases em que precisará solucionar situações-problema customizáveis pelo professor. O jogo ficará disponível na plataforma $\mathrm{REMAR}^{5}$, por meio da qual o professor poderá criar versões customizadas ${ }^{6}$, selecionando fases pré existentes e criando novos conteúdos para os puzzles, de acordo com suas necessidades pedagógicas. Uma vez criada a instância customizada, o professor poderá gerar versões para PC (desktop) e Web, ampliando meios de acesso ao recurso educacional criado. Abaixo são apresentadas as principais características do jogo.

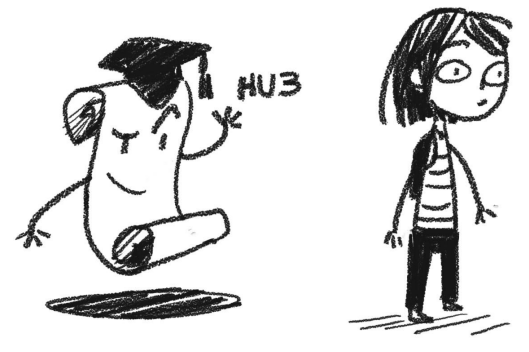

Figura 1: Diploma e a protagonista do jogo

\footnotetext{
4 Plataforma que tem como objetivo facilitar e ampliar a construção e o reuso de jogos educacionais abertos, por meio de um serviço online que oferece ferramentas que facilitam a construção e a customização de jogos. Atualmente a plataforma já abriga alguns jogos educacionais cujos conteúdos podem ser customizados e acessados por meio do endereço http://remar.dc.ufscar.br/.

Uma versão demo pode ser acessada por meio do link http://sistemas2.sead.ufscar.br/loa/EmBuscadoSantoGrau/ e a versão completa do jogo pode ser acessada gratuitamente na plataforma REMAR por meio do seguinte link: http://remar.dc.ufscar.br/resource/show/8

${ }^{6}$ Link para as documentácões que ensinam como customizar o jogo na plataforma REMAR e gerar uma instância jogável https://remar.readme.io/docs/em-busca-do-santo-grau-1. Link para acessar ao vídeo de apresentação do jogo: https://youtu.be/BTpVGEB17O4
} 
VII Congresso Brasileiro de Informática na Educação (CBIE 2018)

Anais dos Workshops do VII Congresso Brasileiro de Informática na Educação (WCBIE 2018)

\subsection{Estética}

A estética do jogo segue um estilo de desenho simplificado, com traços que remetem aos rabiscos e caricaturas que alunos geralmente fazem em seus cadernos (Fig. 1). A escolha por essa estética se deu por dois motivos: a) permitir que o jogo seja executado em diversos computadores sem o risco de dificuldades de desempenho; b) garantir que outras instituições possam desenvolver novas salas e desafios para o jogo em parceria com o LOA, os quais poderão sugerir e até mesmo desenhar seus próprios cenários e personagens apenas seguindo os traços do estilo original, garantindo, assim, um aspecto não finito ao jogo. Atualizações poderão ser agregadas ao jogo sempre que novas demandas surgirem por parte de professores e alunos de diferentes instituições. A possibilidade de criação de fases por outras equipes e instituições também democratiza seu desenvolvimento e amplia as dimensões do jogo.

\subsection{Mecânica}

A mecânica básica de Em Busca do Santo Grau se resume no jogador movimentar a protagonista por cenários 2D, vistos por meio de uma perspectiva Top Down View, ou seja, visão esta em que o jogador observa os cenários de cima para baixo. Por meio da interação com objetos, computadores e personagens, em cada cenário o jogador precisará resolver quebra-cabeças (puzzles) que serão referentes aos conteúdos customizados pelo professor. Para tanto, a personagem poderá ser movimentada utilizando as teclas W, A, S, D e a Tecla E para executar ações (como acessar computadores, interagir com objetos, abrir portas, conversar com outros personagens, etc.). Também será necessária a utilização do mouse nos momentos de resolução de questões específicas (como acessar menus, clicar em imagens e inserir textos).

Também existem outros elementos que influenciam diretamente na jogabibilidade, como Pontuação e Power-Ups. O jogador começará o jogo com um número inicial de 1000 pontos, o qual é alterado de acordo com as ações executadas ao longo do game. Caso o jogador zere seus pontos, ele precisará recomeçar o jogo. Ao longo das fases, será possível coletar Power-Ups, que se tratam de itens que causam alteração na jogabilidade do jogador, auxiliando-o na resolução dos desafios (como aceleração dos movimentos da personagem ou deixar obstáculos em câmera lenta).

\subsection{Pontos de Customização pelo Professor - Apresentação das Fases}

Em Busca do Santo Grau traz um conjunto de salas com diferentes situações-problemas que precisam ser resolvidos linearmente pelo jogador. $\mathrm{O}$ diferencial desse jogo baseia-se na possibilidade de customização desses puzzles, nos quais o usuário poderá personalizar suas questões e alternativas com o conteúdo que desejar. Assim, a estrutura do jogo será baseada em duas fases fixas (uma no início e outra no fim) e fases modulares que poderão ser inseridas ou não no meio do jogo à critério do professor, ou seja, aquelas que apresentam as mecânicas e pontos de customização mais úteis de acordo com suas demandas educacionais.

\section{- Refeitório (Tutorial - Fixa)}

Nesta fase o jogador será introduzido aos controles básicos do jogo. Além disso, será preciso passar por dois obstáculos encontrados na sala, como atravessar uma guerra de 
VII Congresso Brasileiro de Informática na Educação (CBIE 2018)

Anais dos Workshops do VII Congresso Brasileiro de Informática na Educação (WCBIE 2018)

comida sem ser atingido e se esquivar por entre pessoas entrando e saindo do restaurante (Fig. 2). Por ser uma sala tutorial para familiarização dos controles, não será apresentado nenhum tipo de conteúdo ao jogador, portanto o professor não terá a oportunidade de customização nesse caso.

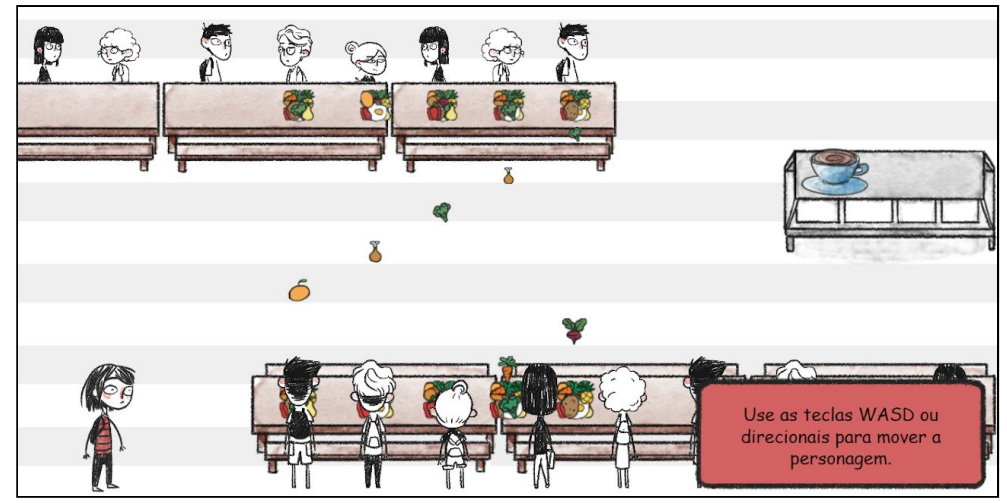

Figura 2: Exemplo do Refeitório, fase tutorial do jogo.

\section{- Sala de Tecnologia (opcional ao professor)}

Nesta sala o jogador terá interação com conteúdos multimídia escolhidos pelo professor. Em um primeiro momento, o jogador deverá acessar um telão no centro da sala para ver o conteúdo disponibilizado pelo professor na internet (ex: vídeos, podcasts, artigos, animações, quadrinhos etc). O acesso poderá ocorrer por meio de hiperlinks que redirecionará o aluno para um site escolhido pelo próprio professor. A inserção deste hiperlink acontecerá por meio da plataforma REMAR, na qual o professor será orientado para inserir os conteúdos e assim exportar sua versão do jogo. Depois que o aluno acessou o conteúdo, ele deverá interagir com três pequenos computadores localizados no início da sala (Fig. 3) nos quais terá de resolver 3 anagramas a fim de liberar a porta de saída.

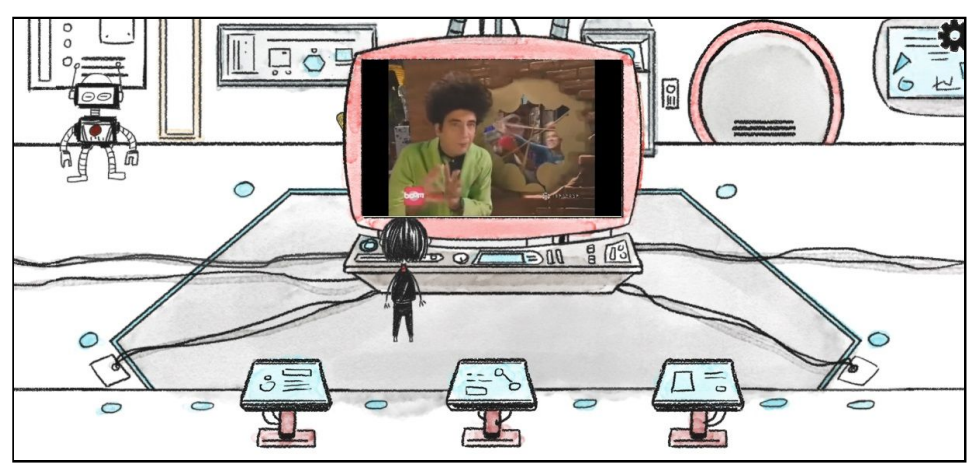

Figura 3: Sala de Tecnologia e interação com os anagramas do jogo.

\section{- Galeria (opcional ao professor)}

A mecânica desta sala consiste na organização de conteúdos ilustrados por quadros na parede de uma Galeria. Assim, o jogador ao interagir com uma parede com quadros localizados no centro da sala, uma tela será aberta mostrando uma sequência de quatro 
VII Congresso Brasileiro de Informática na Educação (CBIE 2018)

Anais dos Workshops do VII Congresso Brasileiro de Informática na Educação (WCBIE 2018)

(ou mais) imagens que deverão ser organizadas de acordo com uma lógica proposta pelo professor. A customização acontece na escolha e combinação das imagens, como partituras, pedaços de código, esquemas de Biologia (Fig. 4) ou outros elementos imagéticos que devem obedecer a uma dada ordenação, um após o outro, para que façam sentido.

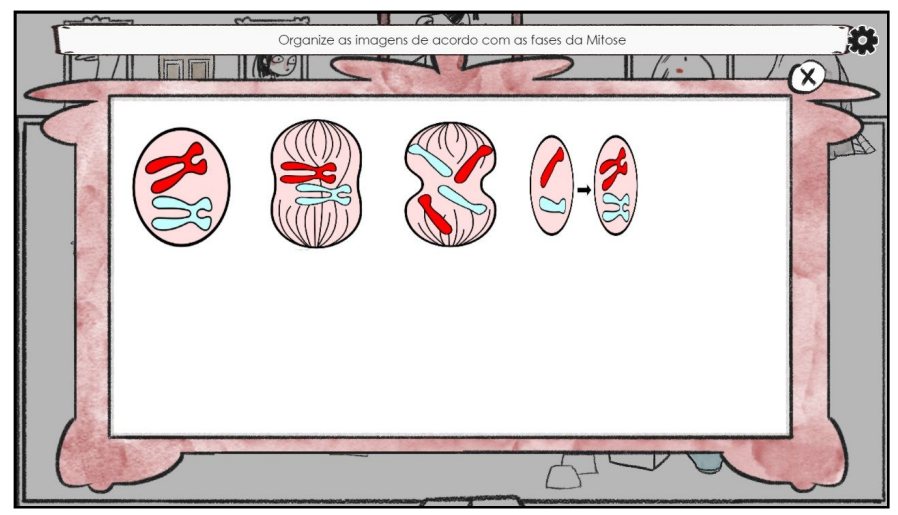

Figura 4: Galeria e interações com imagens de acordo com o conteúdo proposto.

\section{- Sala Final (3 Etapas - Fixa)}

A sala final do jogo será dividida em 3 etapas que apresentam puzzles que exigem uma combinação de agilidade e conhecimentos do jogador acerca do conteúdo proposto.

\section{- Campo Minado}

Etapa em que o jogador se depara com um campo dividido em 4 colunas e 5 fileiras com espaços demarcados como A, B, C, D e E. O desafio desta etapa consiste em o jogador pisar no espaço correspondente à alternativa que ele considera a correta para cada uma das questões que aparecem na tela (customizadas pelo professor). Caso o jogador caminhe na alternativa errada, ele perderá pontos e precisará recomeçar a etapa.

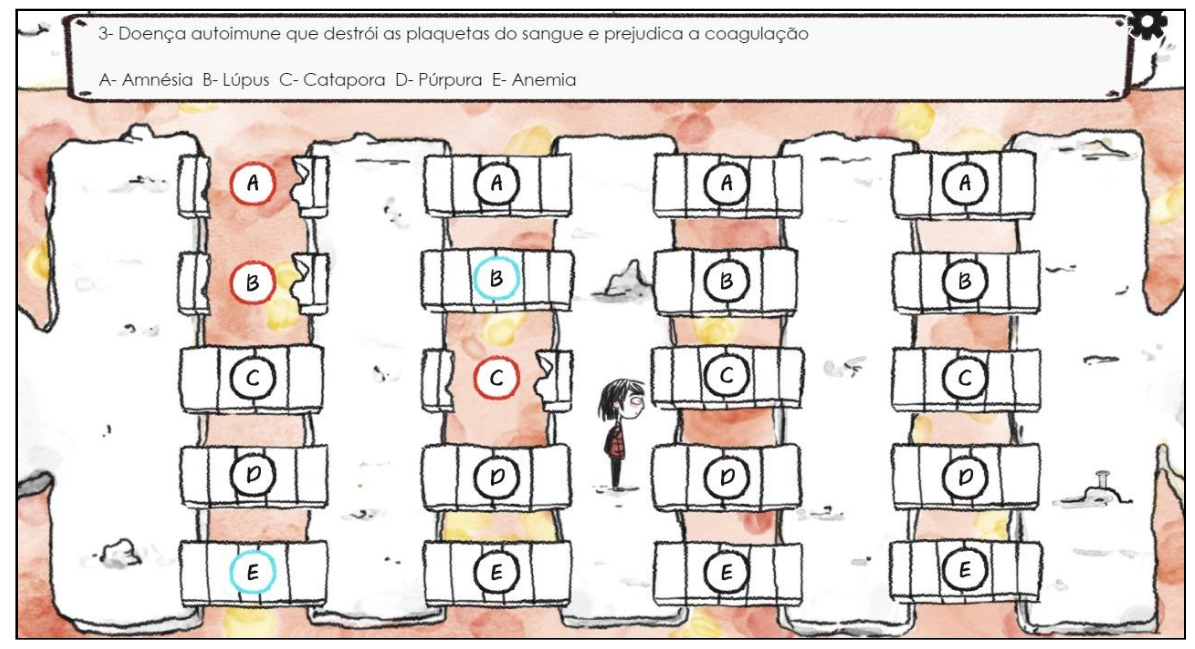

Figura 5: Interação no Campo Minado. 
VII Congresso Brasileiro de Informática na Educação (CBIE 2018)

Anais dos Workshops do VII Congresso Brasileiro de Informática na Educação (WCBIE 2018)

- Blocos de Neve

$\mathrm{Na}$ segunda etapa, o jogador precisa interagir com 3 blocos que estão espalhados e deslizando por uma pista de gelo. Cada bloco (1, 2 e 3) representa uma alternativa correspondente à questão proposta pelo professor e o jogador deverá pegar aquele que considerar a resposta certa. Entretanto, a dificuldade desta sala concentra-se também na captura desses blocos. Após responder 3 ondas de questões por meio da captura correta desses blocos, o jogador poderá avançar para a próxima sala. Contudo, caso ele pegue algum bloco errado, ele será penalizado com a perda de pontos.

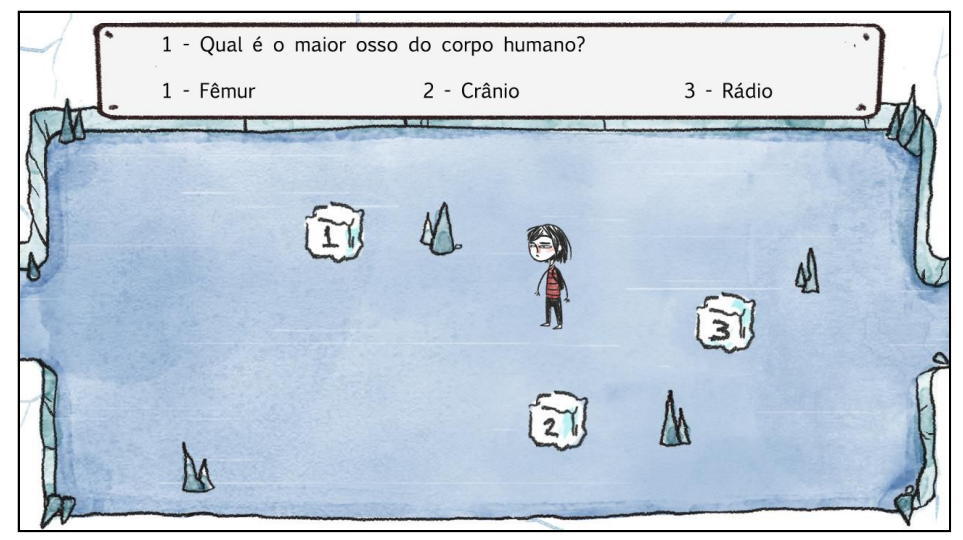

Figura 6: Exemplo de desafio na etapa Blocos de Neve

\section{- Forme-se se For Capaz}

A terceira etapa da última sala consiste na apresentação do Trabalho de Conclusão do Curso, o temido TCC. O jogador deverá enfrentar um monstro de papel que lançará projéteis contra a protagonista que precisará se esquivar. Essa etapa consiste em o jogador responder a 5 questões que valem 2 pontos cada, dentro de um tempo limite antes que o monstro se recupere. Ao fazer um mínimo de 6 pontos, o monstro se transforma em uma pilha de papel e, assim, o diploma se rende à personagem (Fig. 7). Uma vez que o jogador complete a última etapa desta fase, a personagem conseguirá, finalmente, alcançar seu tão sonhado diploma e assim completar o jogo.

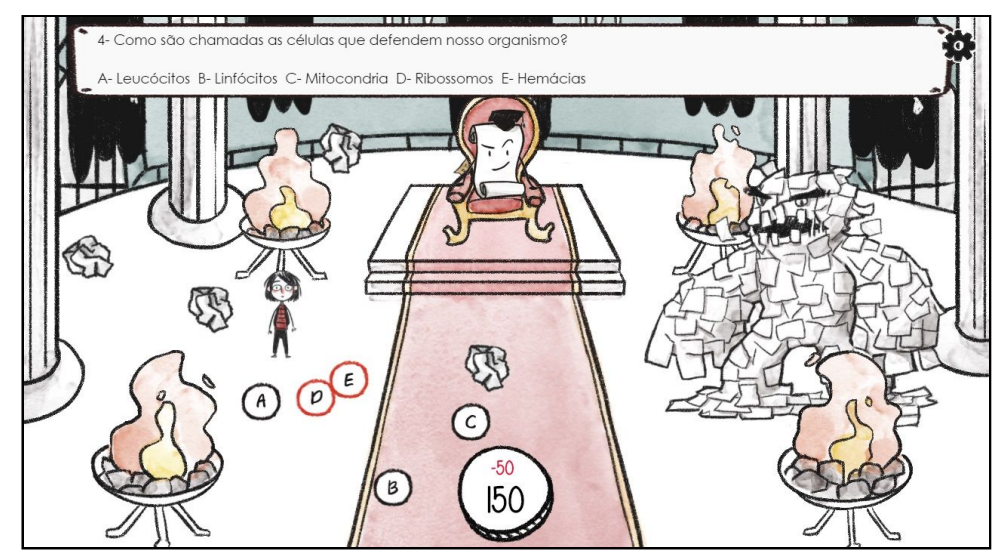

Figure 7: Desafio final em que a protagonista encara seu diploma e o monstro do TCC 
VII Congresso Brasileiro de Informática na Educação (CBIE 2018)

Anais dos Workshops do VII Congresso Brasileiro de Informática na Educação (WCBIE 2018)

\section{Considerações finais}

Em Busca do Santo Grau, portanto, surge como um recurso lúdico, gratuito e inovador a professores que queiram trazer para suas aulas um jogo eletrônico moldável às suas demandas de ensino. Por meio do acesso à plataforma REMAR, é possível que o professor crie uma instância do jogo com seu próprio conteúdo nos desafios do jogo.

Como trabalhos futuros, a equipe do LOA atualmente está desenvolvendo mais duas fases customizáveis que serão acessíveis a pessoas com deficiência visual: um campo de futebol no qual a personagem deverá chutar uma bola ao gol a partir da resolução de cálculos que lhe darão as coordenadas para o chute certeiro (uma mecânica que favorece a customização com desafios cujo resultado seja numérico); e uma biblioteca onde será necessário achar livros mágicos por meio de estímulos sonoros espalhados pelo cenário, com pistas que auxiliarão o jogador a descobrir as palavras escondidas (uma mecânica que favorece qualquer conteúdo didático cujas respostas para os desafios sejam palavras). A ideia é que estes dois novos módulos de jogo permitam que jogadores com diferentes deficiências visuais e videntes possam jogar, com as mesmas condições, de modo a usufruir dos recursos educacionais de forma similar. Os primeiros testes com professores e pessoas com e sem deficiência visual serão realizados no segundo semestre de 2018, tanto para validação do jogo em relação às suas possibilidades de customização e efetividade na inclusão digital de pessoas com deficiência visual, quanto para avaliação das fases acessíveis de acordo com um conjunto de diretrizes de desenvolvimento para jogos educacionais acessíveis.

\section{Referências}

Gee, J. P. (2007). "What video games have to teach us about learning and literacy". New York: Palgrave Macmillan. 2005 .

(2005). "Good video games and good learning”. Phi Kappa Phi Forum, nº 2.

McGonigal. J. (2011) "Reality is broken: why games make us better and how they can change the world". Nova York: The Penguin Press.

Nogueira, D; Chaimowicz, L. e Prates, O (2013). Pingo - An Online Portal for Educational Games with Customizable Content. In "Proceedings of SBGames 2013. XV Brazilian Symposium on Computer Games and Digital Entertainment 2016 Computing Tracks" - Full Papers. São Paulo. 2013.

Salen, K; Torres, R; Wolozin, L; Rufo-Tepper, L and Shapiro A. (2010) Quest to Learn: Developing the School for Digital Kids. In "The John D. and Catherine T. MacArthur Foundation on Digital Media and Learning", English edition. The MIT Press.

Squire, K. (2007). Games, Learning and Society: Building a Field. In "Educational Technology". University of Wisconsin, Madison. 